\title{
Posttraumatic Growth and Its Correlates in an Indian Setting
}

\author{
Shweta Tandon ${ }^{1} *$, Seema Mehrotra ${ }^{2}$
}

\section{ABSTRACT}

The present study aimed at exploring the extent and nature of self reported posttraumatic growth (PTG) as well as the association of posttraumatic growth with psychosocial resources, meaning making, coping \& psychological outcomes following cancer diagnosis in a heterogeneous sample of thirty Indians undergoing treatment at two points. Results indicated that post traumatic growth (PTG) was reported by almost all study participants. Patients in the early stage of the disease reported more positive changes in the aftermath of the diagnosis than those with advanced disease .Among the psychosocial resources, self efficacy, social support and emotional processing and adaptive coping strategies namely information seeking and support seeking were positively related with PTG. Patients with positive and fate illness appraisals also reported higher PTG as did those with lower depression and higher quality of life.

\section{Keywords: Posttraumatic Growth, Psychosocial Resources, Indian Setting}

Cancer is considered to be one of the ten leading causes of death in India. The diagnosis of cancer itself is an emotionally laden one, known to generate psychological distress in affected individuals. Despite the advances in modern medicine, patients often fear the worst upon hearing they have cancer regardless of the extent, site or type of the disease (Pillay, 2001).

However recent research on psychological outcomes has shown that cancer is not a uniformly devastating diagnosis, nor is the presence of severe psychological problems a normative response to this diagnosis. (Zemore \& Shepel,1989). Researchers have used a variety of terms to refer to the such positive changes cited by survivors in the aftermath of major stressors including "positive changes" (Collins et al, 1990), "benefit-construal” or" benefit-finding” (Affleck \& Tennen, 1996), "posttraumatic" (Tedeschi \& Calhoun, 1995) or "stress related" growth (Park, Cohen \& Murch, 1996), and "finding meaning" (Park \& Folkman, 1997).Although these terms have been used interchangeably as all of these share the notion of a 'value-added' state (O'Leary

\footnotetext{
${ }^{1} \mathrm{PhD}$, Assistant Professor, CNBC Hospital, New Delhi, India

${ }^{2} \mathrm{PhD}$, Professor, Dept of Clinical Psychology, NIMHANS, Bangalore, India

*Responding Author

(C) 2016, S Tandon, S Mehrotra; licensee IJIP. This is an Open Access Research distributed under the terms of the Creative Commons Attribution License (http://creativecommons.org/licenses/by/2.0), which permits unrestricted use, distribution, and reproduction in any Medium, provided the original work is properly cited.
} 


\section{Posttraumatic Growth and Its Correlates in an Indian Setting}

\& Ickovics, 1995), it has been argued that these constructs are not entirely equivalent (Butler, 2007).

For the present research, the concept of post traumatic growth was endorsed as a study variable. Post traumatic growth refers to positive psychological changes experienced as a result of the struggle with highly challenging life circumstances”(Calhoun \& Tedesch,2001). Research in the area of post traumatic growth has generated high interest in the last decade and to some extent attempts have been made to explore the dimensions, determinants as well as correlates of PTG

Research has consistently revealed that irrespective of the time of assessment, most patients report experiencing at least one positive change as a result of the cancer experience. These changes could be in terms of greater closeness in personal relationships, increase in spirituality, greater appreciation of one's life and personal strength (Komura and Hegarty, 2006, Widows, 2002).

Studies exploring demographic and clinical correlates of PTG have yielded inconsistent results with some studies indicating that age, income and education were related positively to PTG (Cordova et al, 2007, Manne et al, 2004, Weiss, 2004, Widows, Jacobsen, Carver and Antoni, 2004, Lechner et al ,2003, Cordova, Cunningham , Carlson and Andrykowski, 2001) while others report no such relationship. (Tokgöz, 2008)

However, the research focusing on the links between different psychosocial resources and various domains of PTG has provided promising leads. Social support and religious coping have been shown to be positively related to PTG (Karanci and Ekram, 2007, Schwazer, Luszczynka, Boehmer, Taubert and Knoll, 2006, Urcuyo, Boyers, Antoni and Carver, 2005). Similarly self efficacy has also been shown to have some effect on some dimensions of PTG namely acceptance of life's imperfections and increased sensitivity to others (Luszczynska, Mohamed and Schwarzer, 2005, Schulz and Mohamed, 2004).

Emotional processing involves active attempts to acknowledge and understand one's emotions. The available evidence suggests that although emotional processing is conducive in the initial stages, longer periods of emotional processing could be counterproductive. (Danoff-Burg, 1998, Stanton et al, 2000). A clearer understanding of the nature of association of emotional processing with distress and well being requires further research.

Research in the area of perceived life threat and adaptive coping (especially positive reappraisals) as predictors of PTG have been robust and consistent (Cordova, Andrykowski, 2001, Widows, 2002, Lechner et al 2003, Manne et al, 2004 Schulz and Mohamed, 2004, Luszczynska, Mohamed and Schwarzer, 2005, Kinsinger et al 2006, Bellizi and Blank 2006, 


\section{Posttraumatic Growth and Its Correlates in an Indian Setting}

Cordova et al , 2007). Studies on the association of PTG with indices of adjustment on the other hand are inconclusive and need further examination.

It needs mention that a bulk of the research in this area (PTG) has utilized both cross sectional and longitudinal designs; however most studies have used either survivor- reports or participants diagnosed with breast cancer as their study sample. The studies on recently diagnosed patients with heterogeneous cancer diagnoses as well as those utilizing non-western samples are relatively less frequent (Mehrotra, 2008).

The present study aimed at exploring the extent and nature of self reported posttraumatic growth following cancer diagnosis in a heterogeneous sample of Indians undergoing treatment for cancer. It also attempted to examine the association of posttraumatic growth with psychosocial resources (social support, self efficacy, religiousity/spirituality and emotional processing), meaning making (including the question of "why me" answers to "why me" and illness appraisals) and coping (avoidance, acceptance/resignation, information and support seeking) as well as psychological outcomes (anxiety, depression and quality of life). The study was part of a larger study aimed at exploring search for meaning and meaning-making process in cancer and their correlates in an Indian context.

It was hypothesized that higher levels of psychosocial resources, higher engagement in search for meaning, positive appraisals, higher use of adaptive coping strategies would be associated with higher posttraumatic growth scores at follow-up assessment. No uni-directional hypotheses were formed regarding the relationship of avoidance and acceptance coping and religiousity /spirituality with posttraumatic growth.

\section{METHOD}

\section{Sample}

Thirty recently diagnosed cancer patients with a heterogeneous diagnosis were drawn from four different oncology settings across two cities in India. The four centers where data were collected catered to the needs of patients from varied socio-economic strata. The patients who were unaware of diagnosis or those who were opined by the treating oncologists to have terminal illness, recurrence or those receiving palliative care, were not included in the study sample. Similarly those who were undergoing or who had undergone psychotherapy for dealing with cancer related distress were not included in the study.

The participants were on average 47years old. Further analysis of frequencies revealed that more than of half of the participants were within 36 to 55 yrs age range (belonged to the middle adulthood stage) while a little less than a quarter were 56 years or older. A little more than one tenth of the sample belonged to the young adulthood stage being in the 18-35 years age range. Majority of the participants were Hindu by religion (70\%), were married (73\%) and had 


\section{Posttraumatic Growth and Its Correlates in an Indian Setting}

undergone at least 15 years of formal education (83\%). Both men and women (50\% each) were equally represented in the sample. There was an almost equal distribution of patients who were employed in comparison with those who were not employed. The not employed group predominantly consisted of homemakers.

All patients were undergoing active treatment for cancers diagnosed in the last 1 year (mean duration since diagnosis 3 months). Cancers of the digestive tract (32\%), breast (21\%), genitourinary cancers (14\%) hematological cancers $(12 \%)$ and lung cancers $(7 \%)$ were the commonest diagnoses in the sample. Fifty percent each of the participants were opined by their oncologists to have early stage cancer and advanced stage cancers. Most of them had previously undergone surgery and /or a cycle of chemotherapy/radiation. All patients were receiving chemotherapy as the sole modality of treatment at follow-up. Although the duration since diagnosis for patients at follow-up ranged from 37-210 days, the mean duration was approximately 3 months. There was an equal distribution of patients with duration of diagnosis less than and more than 3 months.

\section{Measures}

\section{Posttraumatic Growth Inventory (PTGI, Tedesdchi \& Calhoun, 1996)}

This inventory assesses positive changes experienced after trauma. It is a 21 item measure that yields a total score and five subscale scores. The subscales are: new possibilities, relating to others, personal strength, spiritual change and appreciation of life. The items are rated on a 6 point Likert scale ranging from " 0 " (I did not experience this change as a result of my crisis to "5" (I experienced this change to a very great degree due to my crisis). In the present study, the respondents were asked to rate the PTGI items in the context of cancer experience. Alpha coefficient for the total PTGI score is 0.90.Internal consistency for the scales ranged from 0.670.85 (Tedeschi \& Calhoun, 1996).

\section{Meaning Making}

\section{Meaning Making Interview Schedule (Developed by researcher)}

A semi-structured interview containing pre-determined probe questions was used to elicit issues related to the meaning making process. The probes were in the form of open ended questions. These pertained to thoughts and feelings about the illness, extent of sharing the same with significant others, presence of and preoccupation with the question of "why me?"(Hardly, sometimes and thinking a lot about why me?) Answers to the question of why me (did not search, still searching and found some answer), one's view of illness and important factors that might have shaped such views. These pre- determined probes were used as and when appropriate in the flow of narratives and the exact phrasing and sequencing of questions were determined by the contextual factors such as the language used by the index participant and the flow of conversation etc. 
Posttraumatic Growth and Its Correlates in an Indian Setting

\section{Coping}

Medical Coping Modes Questionnaire (Fiefel, Strack \& Nagy, 1987 revised by Rodrigue, Jackson \& Perri, 2000)

It is a 19- item questionnaire designed to measure cognitive-behavioral, illness-related coping strategies. In the present study, the 13 item- version of the scale was used as the remaining 6 items have been reported to have insufficient discriminant validity in the factor analytic study by Rodrigue, Jackson and Perri (2000). It provides scores on four subscales labeled "Information seeking”, “Support seeking”, “Avoidance,” and “Acceptance-resignation”. Responses are given on a four-point scale: (1) “Never”, “To a small extent”; (2) “Quite a bit”; (3) and "Very Much”; (4). Rodrigue, Jackson and Perri (2000) reported internal consistency values above 0.70 for information seeking and avoidance subscales but somewhat lower alpha values (0.58 and 0.52) for support seeking and acceptance-resignation subscales.

\section{Psychosocial Resources}

Religious belief salience measure (Blaine \&Crocker, 1995, revised by Exline, Yali \& Sanderson, 2000) Duke's religious index (Koenig, Parkerson \& Meador, 1997)

The revised religious belief salience measure assesses the extent to which religious beliefs influence one's approach to life. It consists of four items that are rated on a 7- point scale wherein " 1 ” indicates “strongly disagree” and “7” indicates "strongly agree”. Higher scores on the scale indicate higher salience of religious beliefs in one's life. Cronbach's alpha has been reported to be 0.90 (Exline, Yali \& Anderson, 2000). The two items of the Duke's religious index refer to social and private and involvement in religious practices respectively and are rated on a six point Likert scale.

\section{Generalized Self Efficacy Scale (Schwarzer \& Jerusalem, 1995)}

This 10 item self- administered scale assesses a general sense of perceived self-efficacy with the aim of predicting coping with daily hassles as well as adaptation upon experiencing various stressful life events. The respondents have to use a four point scale wherein " 1 " indicates "not at all true" and " 4 " indicates "exactly /very true” for rating each statement. Higher scores indicate higher perceived self efficacy. Cronbach's alphas in various studies have ranged from .75 to .91, with the majority being in the high .80s.

\section{Emotional Processing (Stanton, Kirk, Cameron and Burg , 2000)}

The scale on emotional processing consists of 4 items that tap one's general tendency to make active attempts to acknowledge and understand emotions. The respondents are asked to rate the statements on a four-point scale on which " 1 " indicates that they "usually don't do this at all” and " 4 " indicates that they "do this generally". The scale has an internal consistency of 0.72 and test retest reliability of 0.73 and is reported to be uncontaminated by socially desirable responding.

\section{Assessment of Social Support (Part 2, Pillay \& Rao,2002)}

Social support was assessed through a 12- item questionnaire which assessed the perceived availability of social support. It assesses emotional (showing concern, listening), informational 


\section{Posttraumatic Growth and Its Correlates in an Indian Setting}

(giving suggestion, advice, guidance) and instrumental (physical and financial) support. The items are rated on a Likert scale ranging from 1-5 (1=available none of the time and 5=available all the time). Higher scores reflect higher perceived support. Cronbach alpha for the full scale and the test-retest reliability were reported by the authors to be 0.89 and 0.74 respectively.

\section{Psychological Outcome Measures}

\section{Functional Assessment of Cancer Therapy Scale -General (FACT-G, Cella et al, 1993)}

It is a 28 item general cancer quality of life measure for evaluating patients receiving cancer treatment. Data on psychometric properties of the measure are available based on the author's work as well studies from across the globe including India. (Pandey et al. 2005). In the present study, internal consistency of the measure was found to be 0.84 . Higher total scores reflect higher QOL.

\section{Hospital Anxiety and Depression Scale (HADS, Zigmond \& Snaith, 1983)}

It is a 14 item scale and assesses the presence and severity of anxiety and depression. This scale is especially suited for assessment of depression and anxiety in the medically ill as it does not contain depression items that might confound with physical symptoms. It has been extensively tested for use in Indian samples and its applicability for use in cancer patients has been documented by Chaturvedi et al. (1994). In the present study, the internal consistency values for the anxiety and depression scales were 0.82 and 0.88 respectively.

\section{Procedure}

The assessment was carried out in two phases. The first phase called P1 and a second phase (P2) was after a month's interval between the phases. Information on the availability of potential study participants during the data-collection phase was obtained from the doctors. Information available from the treating oncologist and in the medical records was noted after obtaining written informed consent from those patients who fulfilled the study criteria. The semi-structured brief interview was conducted first. Conducting the interviews first was helpful in building rapport through providing a chance for patients to narrate their experiences in response to openended questioning. This helped spontaneous emergence of meaning related themes. The responses were noted down in verbatim to the extent possible during the interview and elaboratenotes were written following the interviews. Audio taping of the interview sessions was not found feasible in the present study- context due to reservations about the same in the participants as well as the practical constraints in the study setting. Audio taping provides rich data while ensuring that problems related to fallibility of recollection and selective attention of the researcher are minimized. However, it is also recognized that sometimes, participants might find it uncomfortable that the interviews are taped and that tense or hostile participants may not provide very useful narratives (Weiss 1994). Prior field experience of the authors suggests that participating in audio-taped research interviews may not be a comfortable and natural process for several Indian participants in oncology settings and influences their willingness to give consent for studies. This was followed by administering the psychosocial resources measures 


\section{Posttraumatic Growth and Its Correlates in an Indian Setting}

(religiousity, spirituality, self efficacy, emotional regulation and processing and social support) as well as measure on coping (MCMQ) to a sample of 30 patients. One month later (P2), the same group of patients were administered post traumatic growth inventory, coping, quality of life and anxiety and depression scales.

\section{RESULTS}

\section{Dimensions and Correlates of Post Traumatic Growth}

The first objective of the study was to explore the extent and nature of self reported post traumatic growth following cancer diagnosis.

The pattern of item endorsements on the PTG Inventory (Table 1) revealed that slightly more than one third $(11 / 30,36.71 \%)$ of the participants reported 'greater closeness with others' as a positive change experienced to a great/very great extent following cancer diagnosis. These items were extracted after a frequency analysis of the items that were highly endorsed (great/very great extent as a result of this crisis) by the patients who reported these positive changes as a result of the cancer diagnosis. Other positive changes commonly reported were accepting that they (patients) could need others support in times of trouble. (30\%), stronger religious faith (26.7\%), being better able to accept things and a greater appreciation of one's own life (26.7\%) and stronger religious faith (26.7\%).

Since the concept/phenomenon of post traumatic growth is relatively new in Indian research and nor much documented work is available, it was also pertinent to analyze what were the changes that patients undergoing treatment did not perceive (Table 2). This took in account those PTG items that were marked as "did not experience this change" following cancer diagnosis by the respondents. Results indicated that a majority (29/30, 96.7\%, Table 2) reported that they did not experience new possibilities becoming available to them nor did they develop any new interests (27/30, 90\%). More compassion for others (83.3\%), discovering a new path for life (80\%) and more willingness to express emotions (80\%) were other items that were infrequently endorsed on the PTG scale.

The second objective of the study was to examine the association of post traumatic growth with other study variables.

\section{Sociodemographic and Clinical Variables}

PTG scores were uncorrelated with age (Spearman correlation was used for analysis on age with two tailed test of significance) and were not different in men and women or across occupational status (The Mann Whitney $U$ test was adopted for between group comparisons of gender and occupational status). The associations of PTG with educational and marital status could not be examined as the sample was highly homogeneous on these variables. 


\section{Posttraumatic Growth and Its Correlates in an Indian Setting}

In order to examine the relationship of the clinical variables and PTG scores, mean scores of participants with varied duration since illness were compared using one-way analysis of variance. The duration since diagnosis was not related to post traumatic growth as the difference between the groups was not statistically significant. As far as other clinical variables was concerned, patients in the early stage of the disease reported more positive changes in the aftermath of the diagnosis than those with advanced disease since the groups were statistically different( Mann Whitney test, $\mathrm{U}=61.00, \mathrm{p}=0.033$.)

\section{Psychosocial Resources and PTG}

The association between psychosocial resources and PTG revealed modest to high correlation between psychosocial resources and PTG scores with social support ( $r h o=0.39, p=0.01$ ), self efficacy (rho=0.33, $\mathrm{p}=0.03$ ) and emotional processing ( $\mathrm{rho}=0.64, \mathrm{p}=0.00$ ) being positively correlated with post traumatic growth and emotional processing reporting the highest correlation among them . Patients who were higher on religious practice 'tended' ( $r h o=0.29, \mathrm{p}=0.06$ ) to report higher post traumatic growth. On the whole, the hypothesis that higher psychosocial resources would be correlated with higher PTG was supported except that religious beliefs scores were not correlated with PTG

\section{Meaning Making and PTG}

Comparisons between those patients thinking 'hardly about why me' with those 'sometimes thinking about why me' revealed that the former had significantly lower PTG than the latter (Mean and S.D $15.57 \&$ 9.00 \& $42.64 \& 31.12$ respectively). It was interesting to note that the think a lot group did not have significantly higher PTG (Mean and S.D 29.00\& 23.68) than the group which did not engage in search for meaning .In other words, as hypothesized, the patients with modest preoccupation with the search for meaning reported greater post traumatic growth than those who did not engage in such a search. However the high preoccupation with searchgroup and non-engagement in- search for meaning group were not significantly different in reports of PTG. (Kruskal-wallis test, $\chi^{2}=4.11$, NS*).

Similarly individuals endorsing different answers to 'why me' at point one did not differ from each other on PTG .Although the group that reported not having searched for an answer had lower PTG scores (Mean and S.D $=16.25 \& 12.28$ ) than those who reported that they had found an answer/accepted lack of answer (Mean and S.D $=33.77 \& 29.80$ ), the overall difference between the three groups was not significant. (Kruskal-Wallis test $\chi 2=1.36$, NS).

In the present research, the interview data was content analyzed to arrive at illness appraisals. The protocols were discussed in detail and common themes were collated to document illness appraisals. Through this process, the illness appraisal categories that were arrived at were, Illness as Part of Life, God's Plan, Challenge, Value, Burden, Punishment, Enemy, Loss, Weakness, Strategy, Relief, Fate and Low threat. Based on the interview data, specific categories of illness 


\section{Posttraumatic Growth and Its Correlates in an Indian Setting}

meanings with the same valence were collapsed to form broader, positive and negative categories and were used for subsequent analyses. The detailed procedure for arriving at illness procedure is described in detail in a previous paper of the author.

With regard to illness appraisals, it was expected as per the theoretical and empirical literature that both low threat and negative appraisals at point one may be linked to lower PTG at point two for different reasons. Low threat appraisals suggest insufficient level of threat and low possibility of further processing and thereby less chance of PTG. Negative appraisals contain themes that are inconsistent with themes of positive changes/PTG Hence for PTG analysis, these two subgroups were combined and compared with the rest of the patients exhibiting positive and fate appraisals. This strategy was considered theoretically meaningful and it also helped ensure sufficient size of the two groups being compared.. The patients exhibiting low threat or negative appraisals at point 1 tended to report lower PTG than others who exhibited positive and fate appraisals as hypothesized(Mann-Whitney $U$ test, $U=70.00, p=0.05$ ).

\section{Coping and PTG}

Findings regarding coping strategies in the present study revealed that information seeking was positively related to PTG at both points though the magnitude of the relationship was stronger for information seeking at point one and PTG at point two rather than when both were examined cross-sectionally at point two.(p1 rho=0.36,p=0.02 \& p2 rho=0.30 ,p=0.05). In other words, patients who had employed information seeking as a coping strategy to deal with illness and treatment demands at point 1 reported greater levels of post traumatic growth when assessed at follow-up.

Support seeking at point 1 showed a trend towards positive correlation $(0.29, \mathrm{p}=0.059)$ with PTG at follow up. Acceptance/resignation at point 1 as a coping strategy exhibited a positive trend towards correlation (rho=0.33, $\mathrm{p}=0.07$ ) with PTG although acceptance-resignation at point 2 was uncorrelated with PTG in cross-sectional analysis. Further analysis indicated that the positive trend between acceptance-resignation at point 1 and PTG reports at point 2 was contributed by one of the three items on the acceptance-resignation scale namely "How often do you feel like just giving up your fight/efforts against your illness.”

Avoidance coping mode at point 1 was uncorrelated with PTG scores at point 2. In the present study, levels of avoidance coping in the very initial phase did not provide predictive information on levels of PTG subsequently reported, after one month interval. On the other hand, avoidance coping at follow-up and PTG had a larger magnitude of negative correlation which failed to reach the required significance level in two tailed test of significance.

On the whole, the hypothesis that PTG scores would be correlated with coping was partially supported in as much as information seeking (at point 1 \& 2) was positively correlated with PTG 


\section{Posttraumatic Growth and Its Correlates in an Indian Setting}

and support seeking at point 1 showed a trend towards positive correlation with PTG.as well as acceptance resignation at point 1 was correlated with PTG at follow up.

\section{Psychological outcomes and PTG}

Theoretical frameworks on PTG (Tedeschi \& Calhoun, 1995, 2004) postulate distress and growth to be distinct rather than as two poles of a single continuum and asserted that distress and growth can co-exist. In the present study PTG was uncorrelated with anxiety whereas there was a trend of PTG exhibiting a positive correlation with quality of life (rho=0.31, p=0.098) and negative correlation with depression $(r h o=-0.33, p=0.076)$ when all outcomes were examined cross-sectionally at point two .The magnitude of correlations indicated that PTG shared only 10$11 \%$ of variation in common with Quality of life and depression. This observation reiterates the need to examine PTG as a construct independently of depression, anxiety or quality of life and suggests that low depression, better quality of life and higher growth experiences may not necessarily go hand in hand.

\section{DISCUSSION}

In the present research, post traumatic growth was reported by almost all study participants reiterating what has been observed in previous research that patients diagnosed with cancer do report at least one positive change despite facing a life threatening illness(Komura and Hegarty,2006,Widows,2002,Sears, Stanton and Danoff-Burg ,2003). . Patients described being less concerned with “trivial matters” post the cancer diagnosis (O’Connor et al, 1990).

Most participants reported greater closeness with others and to some extent reflects what has been documented in previous research. (Andrykowski, Brady \& Hunt, 1993, Fife, 1994 and Teo, Teo \& Teo, 2007). Other areas that patients experienced positive changes were having stronger religious faith similar to Ferrell et al (1992), being better able to accept things, a greater appreciation of their own life similar to Ersek, Ferrell, Dow and Melancon (1997) and realizing that they could depend on others for support in times of trouble.

Although cancer can be viewed at times as a life changing illness, not all domains of one life seem to be affected by such a diagnosis. More than $90 \%$ of the participants reported that they did not experience new possibilities becoming available to them or did not develop any new interests. Other areas that patients did not experience change were 'more compassion for others', 'a new path for life' and 'more willingness to express emotions'. Previous research also supports these findings (.Cordova, Cunningham, Carlson and Andrykowski, 2001) and therefore makes it important in future research to understand how the cancer experience is viewed by patients.

In line with previous research, the present study also was unable to document any associations between sociodemographic variables and Post traumatic growth. (Cordova et al, 2001; Sears et al, 2003; Bhushan \& Hussain, 2007). 


\section{Posttraumatic Growth and Its Correlates in an Indian Setting}

As far as clinical variables are concerned, patients in the early stage of the disease reported more positive changes in the aftermath of the diagnosis than those with advanced disease. The literature reviewed earlier does not yield conclusive data on the association between disease severity and PTG, though a few studies suggest that objective severity indices may be unrelated to PTG whereas perception of cancer as a traumatic stress may be associated with greater PTG(Cordova et al,2007).On the other hand ,a study by Bellizi and Blank(2006) reported differential endorsement of PTG domains in patients with localized disease, those with regional spread and those with invasive disease. In the present study, practical constraints resulted in coding of cancer severity as early and advanced and further refinement in documentation of staging could not be made. Moreover no direct information was available regarding perception of prognosis/change. Although threat perception has been considered as a facilitator of PTG, it is plausible that the relationship between PTG and trauma -exposure may be curvilinear (Fontana \& Rosenheck, 1998).

The duration since diagnosis was not related to post traumatic growth. Research on duration since diagnosis has revealed mixed findings. Some researchers have reported greater PTG when the time since diagnosis is longer (Cordova et al, 2001) whereas others have reported that PTG is reported even when time since diagnosis/trauma is brief (Weiss, 2004; Frazier ,Conlon \& Glaser, 2001).

\section{Psychosocial Resources and PTG}

Social support was positively correlated with post traumatic growth as also observed in previous research. The researcher speculated that patients who reported to be receiving higher social support would have been able to discuss freely issues about the illness and treatment. Subsequently "supportive others could have aided in post traumatic growth by providing a way to craft narratives that could be integrated into schema change". (Niemeyer, 2001; Tedeschi \& Calhoun, 1996).Studies have reported that appropriate social support may promote growth related to interpersonal relationships, such as sense of closeness to others (Tedeschi \& Calhoun, 1996). Social support may have a direct affect on benefit finding (Cadell, Regher, \& Hemsworth, 2003; Karanci \& Erkam, 2007; Kinsinger et al., 2006). It can also facilitate coping and thus change the threat nature of stress (Bandura, 1997).

In the present research self efficacy was positively correlated with PTG.. Self-efficacy beliefs reflect personal action control or agency and an optimistic and confident view of one's self and one's future. Thus self-efficacy may enhance focusing on opportunities for personal gains and growth (Bandura, 1997) and hence after a traumatic life event, people are more likely to find benefits and gains if they have strong self-efficacy. Similar results have also been obtained by Luszczynska, Mohamed and Schwarzer (2005) and Sandoval (2006). 


\section{Posttraumatic Growth and Its Correlates in an Indian Setting}

Emotional processing was another variable that was positively associated with PTG. The theoretical model of PTG proposed by Tedeschi and Calhoun $(1995,2004)$ incorporates the role of cognitive processing in rebuilding of basic cognitive schema that may be shaken/shattered in the aftermath of trauma. It is also proposed that the initial cognitive processes may be more automatic and ruminative in nature. Similarly the organismic valuing theory of growth (Joseph \& Linley,2005) suggests that growth implies construction of 'new world views' and accommodation of situational information in a positive direction could facilitate positive changes in post trauma assumptions. Both these models thus contain the hypothesis that high levels of cognitive processing could play a beneficial role in PTG. The observation in the present study that individuals higher on emotional processing( as reported at point one) reported higher PTG at follow-up is in line with such a theory driven hypothesis.

Patients who were higher on religious practice 'tended' to report higher post traumatic growth. The researcher speculated that for these participants higher habitual engagement in religious practice might have enhanced utilization of religious coping (by means of increased participation in private and social religious activities) which over time could facilitate perception of PTG to some extent especially in the domain of spiritual change. Ho, Chan and Ho (2004) also reported positive change in self, life orientation and spirituality following occurrence of cancer.

\section{Search For Meaning, Meaning Making and Illness Appraisals and Post Traumatic Growth}

The low search for meaning group at point one had lower PTG at point 2 than the group reporting modest engagement in search for meaning ('sometimes thought about why me'). However the latter group did not differ from the high engagement group that reported thinking a lot about why me at point 1 .This suggests that very high preoccupation with 'why me' at point one may not be associated with relatively high PTG at point two as high preoccupation could be a marker of ruminative thinking.

Individuals endorsing different answers to 'why me' at point one did not differ from each other on and this could be attributed to the rather small number of individuals who endorsed that they "did not search for an answer". The patients exhibiting low threat or negative appraisals at point 1 tended to report lower PTG than others who exhibited positive and fate appraisals as hypothesized (Thombre, Simonton \& Sherman, 2010).

\section{Coping and PTG}

Adaptive coping strategies namely information seeking and support seeking were positively related with PTG. It is likely that information seeking might have enhanced a sense of mastery over the situation which could have contributed to reports of positive changes at point two. Similarly it was speculated that support seeking as a coping mode in the initial phase might provide opportunities to experience closeness with significant others and their attempts at care and thereby might contribute to reports of PTG at point 2. Thus adaptive coping strategies as 


\section{Posttraumatic Growth and Its Correlates in an Indian Setting}

mentioned above led to experience of PTG and was similar to Sandoval (2006) findings of a positive relationship between approach coping and PTG .

Acceptance/resignation as a coping strategy exhibited a positive trend towards correlation with PTG. It is speculated that accepting life's imperfections and consequent reprioritizing one's life might be associated with higher PTG reports over time.

Avoidance coping mode at point 1 and point 2 were uncorrelated with PTG scores at point 2. Longitudinal studies are likely to bring more clarity on the dynamic association between avoidance and PTG over time.

\section{Meaning of PTG scores and their potential adaptive significance}

The observation that PTG shared only $10-11 \%$ of variation in common with Quality of life and depression reiterates the need to examine PTG as a construct independently of depression, anxiety or quality of life and suggests that low depression, better quality of life and higher growth experiences may not necessarily go hand in hand. In some of the prior research, depression has been reported to be negatively correlated with PTG (Frazier et al, 2001; Updegraff ,Taylor, Kemeny \& Wyatt ,2002).However research on the positive relationship of PTG and quality of life has yielded mixed results, some researchers reporting a positive relationship and others reporting no relationship at all (Steel, Gamblin \& Carr,2008).

Zoellner and Maercker (2006) in their review of empirical studies on the relationship between PTG and other adjustment outcomes concluded that there was an inconclusive picture regarding the adaptive significance of PTG. However it was also noted that all longitudinal studies find modest positive relationship between perceived growth and adjustment. It was further speculated that when PTG and adjustment indices/distress are measured concurrently, a null relationship could be due to the fact that for some, the perception of PTG may be reflective of ongoing coping efforts whereas for others it may be a signal of successful outcome of coping.

There is consistent evidence that normal perception is marked by mild and robust positive illusions, self enhancement, unrealistic optimism and an exaggerated perception of perceived control. These may represent reserve resources that assume special importance in coping with highly stressful events. Neuroimmunological as well as health promoting behaviour mechanisms have been evoked as some of the explanations for the beneficial effects of positive psychological states on subjective well being as well as physical status during the course of disease. Recovery from traumatic events may involve restoring subtle/modestly positive illusions regarding self, future and relationships. (Taylor, Kemeny, Reed, Bower \& Grunewald, 2000). Along similar lines, McFarland and Alvaro (2001) provided evidence that perceptions of personal improvement may at least in part reflect motivated illusions sustained through derogation of one's past and aimed at coping with threatening events. In fact, Maercker and Zoellner (2006) proposed a two 


\section{Posttraumatic Growth and Its Correlates in an Indian Setting}

component Janus face model of PTG. Herein self perceived growth is seen as having a functional and constructive side as well as an illusory component and that both may co-exist. Thus presence of PTG may at least in part be distortions that help individuals counterbalance distress. It is further proposed that the self deceptive side of PTG may not always be maladaptive especially if it co-exists with deliberate thinking about trauma and does not preclude active coping. It may in such a case be useful as a short term adaptive palliative coping. The realistic component is expected to correlate positively with adjustment over long run. While the illusory component is theorized to decrease over time and constructive self-transformation component is expected to increase over time. This model has been used to explain why PTG tends to show positive correlation with adjustment over time whereas mixed findings in cross-sectional research may be due to unknown proportions of constructive and illusory components of self perceived growth.

Although the possibility of an illusory component in self reports of PTG cannot be ruled out in the present study, there are a few observations enumerated below that support the conjecture that the obtained PTG scores may at least partly represent actual positive changes as well as that PTG may have potentially adaptive significance.

Firstly reports of positive changes were not just obtained through PTG inventory but also emerged in the spontaneous narratives of the participants. Also, these themes co-occurred and were interspersed with themes of distress indicating that the positive changes reported were not completely representative of the operation of denial of distressing realities.

Secondly PTG reports were lowest in those who did not report engagement in search for meaning as well as in those who had low threat/negative appraisals at point one. This is in line with the theoretically expected links between meaning making process and experience of PTG. Moreover, illness appraisal categories were assigned by the researcher (based on interview data) and PTG scores were obtained through self report questionnaire. The tentative links between these two variables emerged despite different methods of measurement. Finally in cross-sectional analyses, reports of higher levels of PTG co-existed with higher levels of active coping such as information seeking and support seeking. This pattern points to the potentially adaptive significance of PTG in the present study. In addition, the trend of modest correlation with lower depression and higher quality of life points in the same direction.

The present research however had certain limitations, Firstly awareness of prognosis was not formally assessed and analyzed and the role of individual differences in perceptions of prognosis could not be clearly examined. Secondly the accounts of psychosocial resources could have been subjected to biases and may not reflect pre-cancer levels of these variables. Thirdly stability of the reports of posttraumatic growth and correspondence with reports of significant others and relationships of PTG with other outcomes over time need to be examined through longitudinal study designs to understand more clearly the adaptive significance of PTG. 


\section{Posttraumatic Growth and Its Correlates in an Indian Setting}

Further research may also focus on uncovering the conditions under which self reported positive changes may get consolidated, weakened or strengthened over time. Finally apart from post traumatic growth, other positive outcomes such as positive affect states were not examined which would have given a more holistic picture.

\section{CONCLUSION}

The findings of the present study highlighted that cancer patients even in the initial phase following diagnosis perceived and reported positive changes in various dimensions of self. It also brought into focus the need for reiterating to the health professionals the role of psychosocial variables in impacting quality of life of cancer patients undergoing active treatment and dialoguing regarding potential ways of modifying health delivery systems that make them more sensitive and responsive to the psychological needs of the patients.

\section{Acknowledgments}

The author appreciates all those who participated in the study and helped to facilitate the research process.

\section{Conflict of Interests}

The author declared no conflict of interests.

\section{REFERENCES}

Affleck, G., \& Tennen, H. (1996). Construing benefits from adversity: Adaptational significance and dispositional underpinnings. Journal of Personality, 64, 899-922.

Andrykowski, M.A., Brady, M.J., \& Hunt, J.W. (1993). Positive psychosocial adjustment in potential bone marrow transplant recipients: Cancer as a psychosocial transition.PsychoOncology,2, 261-276.

Bandura, A. (1997). Self-efficacy: The exercise of control. New York: Freeman.

Bellizzi, K.M., \& Blank, T.O. (2006).Predicting posttraumatic growth in breast cancer survivors. Health Psychology, 25(1), 47-56.

Bhushan, B., \& Hussain, D. (2007).Posttraumatic Growth: Theory, research and issues. Psychological Studies, 52(1), 45-53.

Blaine, B., \& Crocker, J. (1995).Religiousness, race and psychological well being: Exploring social psychological mediators. Personality and Social Psychology Bulletin, 21, 1031-1041.

Butler, L. D. (2007). Growing pains: Commentary on the field of posttraumatic growth and Hobfoll and colleagues' recent contributions to it. Applied Psychology: An International Review, 56(3), 367-378.

Cadell, S., Regehr, C., \& Hemsworth, D. (2003). Factors contributing to posttraumatic growth: A proposed structural equation model. American Journal of Orthopsychiatry,73(3), 279-287.

Calhoun, L.G., \& Tedeschi, R.G. (2001).Posttraumatic growth: The positive lessons of loss. In R.A.Neimeyer (Ed.), Meaning reconstruction and the experience of loss (pp. 157172).Washington, D.C: American Psychological Association. 


\section{Posttraumatic Growth and Its Correlates in an Indian Setting}

Cella, D.F., Tulsky, D.S., Gray, G., Sarafian, B., Linn, E., Bonomi, A., et al.(1993). The Functional Assessment of Cancer Therapy scale: development and validation of the general measure. Journal Of Clinical Oncology,11 (3), 570-579.

Chaturvedi ,S.K., ,Chandra ,P.,Channabasavanna ,S.M.,Beena,M.B.,\& Pandian,R.D. (1994).

Detection of anxiety and depression in cancer patients. NIMHANS Journal,12,141-144.

Collins, R. L., Taylor, S. E., \& Skokan, L. A. (1990). A better world or a shattered vision? Changes in perspectives following victimization. Social Cognition, 8, 263-285.

Cordova ,M.J., Giese-Davis ,J., Golant ,M., Kronenwetter ,C., Chang ,V.,\& Spiegel ,D.(2007). Breast cancer as trauma: Posttraumatic stress and Posttraumatic growth. Journal of Clinical Psychology in Medical Settings, 14,308-319.

Cordova, M. J., Cunningham, L. L., Carlson, C. R., \& Andrykowski, M. A. (2001). Posttraumatic growth following breast cancer: A controlled comparison study. Health Psychology, 20, 176-185.

Ersek, M., Ferrell, B.R., Dow, K.H.,\& Melancon, C.H.(1997). Quality of life in women with ovarian cancer. Western Journal of Nursing Research, 19 (3), 334-350.

Exline, J.J., Yali, A.M.,\& Sanderson, W.C.(2000). Guilt, discord, and alienation: the role of religious strain in depression and suicidality. Journal Of Clinical Psychology, 56 (12), 1481-1496.

Ferrell, B., Grant, M., Schmidt, G.M., Rhiner, M., Whitehead, C., Fonbuena, P., \& Forman, S.J.(1992). The meaning of quality of life for bone marrow transplant survivors. Part 1. The impact of bone marrow transplant on quality of life. Cancer Nursing, 15 (3), 153-60.

Fiefel, H., Strack, S., \&Nagy, V.T. (1987).Degree of life threat and differential use of coping modes. Journal of Psychosomatic Research, 31, 91-99.

Fife, B.L. (1994). The conceptualization of meaning in illness. Social Science and Medicine, 38, 309-316.

Fontana, A., \& Rosenheck, R. (1998).Psychological benefits and liabilities of traumatic exposure in the war zone. Journal of Traumatic Stress, 11,485-505.

Frazier, P., Conlon, A., \& Glaser, T. (2001).Positive and negative life changes following sexual assault. Journal of Consulting and Clinical Psychology, 69, 1048-1055.

Ho, S.M., Chan, C.L.,\& Ho,R.T(2004).Post traumatic growth in Chinese cancer survivors. Psycho-Oncology, 13(6), 377-389.

Joseph, S., \& Linley, P.A. (2005).Positive adjustment to threatening events: An organismic valuing theory of growth through adversity. Review of General Psychology, 9,262-280.

Karanci, N.A., \& Erkam, A. (2007).Variables related to stress -related growth among Turkish breast cancer patients. Stress and Health, 23, 315-322.

Kinsinger ,D.P., Penedo ,F.J.,Antoni ,M.H.,Dahn ,J.R.,Lechner ,S.,\& Schneider man ,N.(2006). Psychosocial and socio-demographic correlates of benefit-finding in men treated for localized prostate cancer. Psycho-Oncology, 15 (11), 954-61.

Koenig, H.G., Parkerson, G.R. Jr., \& Meador, K.G. (1997). Religion index for psychiatric research. The American Journal of Psychiatry, 154 (6), 885-856. 


\section{Posttraumatic Growth and Its Correlates in an Indian Setting}

Komura, K., \& Hegarty, J.R. (2006). The appraisal of positive life changes following cancer diagnosis: An interview study. Palliative and Supportive Care, 4, 3-12.

Lechner,S.C.,Zakowski,S.G.,Antoni,M.H.,Greenhawt,M.,Block,K.,\&Block,P.(2003).Do sociodemographic and disease related variables influence benefit finding in cancer patients?.Psycho-Oncology, 12(5), 491-450.

Luszczynska, A., Mohamed, N., \& Schwarzer, R. (2005). Self-efficacy and social support predict benefit finding 12 months after cancer surgery: The mediating role of coping strategies. Psychology, Health \& Medicine, 10 (4), 365-375.

Manne, S.L, Ostroff ,J.S, Winkel ,G., Goldstein ,L., Fox ,K., \& Grana ,G.(2004).Posttraumatic growth after breast cancer: Patient, partner and couple perspectives. Psychosomatic Medicine, 66(3), 442-454.

McFarland, C., \& Alvaro, A. (2001). The impact of motivation on temporal comparisons: Coping with traumatic events by perceiving personal growth. Journal of Personality and Social Psychology, 79(3), 327-343.

Mehrota, S. (2008).Psycho-Oncology research in India: Current status and future directions. Journal of the Indian Academy of Applied Psychology, 34(1), 7-18.

Neimeyer, R. (2001).Meaning reconstruction and the experience of loss. Washington, DC: American Psychological Association.

O’Connor, A.P., Wicker, C.A. \& Germino, B.B. (1990).Understanding the cancer patient's search for meaning. Cancer Nursing, 13, 167-175.

O’Leary, V.E., \& Ickovics, J.R. (1995).Resilience \& thriving in response to challenge: An opportunity for a paradigm shift in women's health .Women's Health: Research on Gender, Behaviour and Policy, 1,121-142.

Pandey, M., Thomas, B. C., Ramdas, K., \& Nanda Mohan, V. (2005).Factors influencing distress in Indian cancer patients.Psycho-Oncology,15(6),547-550.

Park, C. L., Cohen, L., \& Murch, R. (1996). Assessment and prediction of stress-related growth. Journal of Personality, 64, 71-105.

Park, C.L., \& Folkman, S. (1997). Meaning in the context of stress and coping. Review of General Psychology, 1(2): 115-144.

Pillay, A. L. (2001). Psychological symptoms in recently diagnosed cancer patients.South African Journal of Psychology, 31(1),14-19.

Pillay, U., \&Rao, K. (2002). The structure and function of social support in relation to helpseeking behaviour. Family Therapy, 29(3), 153-167.

Rodrigue, J.R., Jackson, S., \& Perri, M.G. (2000).Medical Coping modes Questionnaire: Factor structure for adult transplant candidates. International Journal of Behavioural Medicine, $7(2), 89-111$.

Sandoval, J. A. (2006). Correlates of benefit finding in men treated for stage I or II prostate cancer. Dissertation Abstracts International: Section B: The Sciences and Engineering, 66(12-B), 6934. 


\section{Posttraumatic Growth and Its Correlates in an Indian Setting}

Schulz, U., \& Mohamed, N.E. (2004).Turning the tide: Benefit finding after cancer surgery. Social Science and Medicine, 59(3), 653-662.

Schwarzer, R., \& Jerusalem, M.(1995).Generalized self efficacy scale. In J.Weinman, S.Wright, \& M.Johnson (Eds.), Measures in health psychology :A users portfolio. (pp.35-37).U.K: NFER-NELSON.

Schwarzer, R., Luszczynska, A., Boehmer, S., Taubert, S., \& Knoll, N.(2006). Changes in finding benefit after cancer surgery and the prediction of well-being one year later. Social Science and Medicine, 63 (6), 1614-24.

Sears, S.R., Stanton, A. L., \& Danoff-Burg, S. (2003). The yellow brick road and the emerald city: Benefit finding, positive reappraisal coping, and posttraumatic growth in women with early-stage breast cancer. Health Psychology, 22(5), 487-497.

Stanton, A. L., Kirk, S. B., Cameron, C. L., \& Danoff-Burg, S. (2000). Coping through emotional approach: Scale construction and validation. Journal of Personality and Social Psychology, 78, 1150-1169.

Steel, J.L., Gamblin, T.C., \&Carr, B.I. (2008). Measuring post-traumatic growth in people diagnosed with hepatobiliary cancer: Directions for future research. Oncology Nursing Forum, 35(4), 643-650.

Taylor, S. E., Kemeny, M. E., Reed, G.M., Bower, J. E., \& Gruenewald, T. L. (2000). Psychological resources, positive illusions, and health. American Psychologist, 55(1), 99-109.

Tedeschi, R. G. \& Calboun, L. G. (2004b). A clinical approach to posttraumatic growth. In P. A. Linley \& S.Joseph (Eds.) Positive psychology in practice(pp. 405-419). Hoboken, New Jersey: Wiley.

Tedeschi, R. G., \& Calhoun, L. G. (1996).The Posttraumatic Growth Inventory: Measuring the positive legacy of trauma. Journal of Traumatic Stress, 9, 455-471.

Tedeschi, R.G.,\& Calhoun, L.G.( 1995). Trauma and transformation: Growing in the aftermath of suffering.Thousand Oaks, CA: Sage.

Teo,C.K., I. E. Teo,I.E., \& Teo,C.B(2007) Post-traumatic Growth in Cancer: Perspectives of Indo-Malaysian Patients . The Internet Journal of Family Practice 5( 1)

Thombre, A., Sherman, A.C \& Simonton, S.(2010). Posttraumatic growth among cancer patients in India. Journal of Behavioral Medicine, 33(1),15-23.

Tokgöz.G., Yalug,I., Özdemir.S .,Yazici.A., Uygun.,K \& Aker.T(2008). The Prevalance Of Posttraumatic Stress Disorder and Posttraumatic Growth In Patients With Cancer.Yeni Symposium 46(2).

Updegraff, J. A., Taylor, S. E., Kemeny, M. E., \& Wyatt, G. E. (2002).Positive and negative effects of HIV infection in women with low socioeconomic resources. Personality and Social Psychology Bulletin, 28, 382-394.

Urcuyo, K.R., Boyers, A.E., Carver, C.S. \& Antoni, M.H. (2005). Finding benefit in breast cancer: Relations with personality, coping, and concurrent well-being. Psychology and Health, 20(2), 175-192.

Weiss, T. (2004).Correlates of post traumatic growth in married breast cancer survivors. Journal 


\section{Posttraumatic Growth and Its Correlates in an Indian Setting}

of Social and Clinical Psychology, 23,733-747.

Widows, M. R. (2002). Individual differences in posttraumatic growth following bone marrow transplantation. Dissertation Abstracts International: Section B: The Sciences and Engineering, 62(11-B), 5398.

Widows, M.R., Jacobsen, P.B., Booth-Jones, M., \& Fields, K. K.(2005).Predictors of Posttraumatic Growth Following Bone Marrow Transplantation for Cancer. Health Psychology, 24(3), 266-273.

Zemore, R., \& Shepel, L. F. (1989). Effects of breast cancer and mastectomy on emotional support and adjustment. Social Science and Medicine, 28, 19-27.

Zigmond, A.S., \&Snaith, R.P.(1983).The Hospital Anxiety and Depression Scale. Acta Psychiatrica Scandinivica,67(6),361-370.

Zoellner, T., \& Maercker, A. (2006).Posttraumatic growth in clinical psychology-A critical review and introduction of a two component model. Clinical Psychology Review, 26,626-653.

How to cite this article: S Tandon, S Mehrotra (2016), Posttraumatic Growth and Its Correlates in an Indian Setting, International Journal of Indian Psychology, Volume 4, Issue 1, No. 69, ISSN:2348-5396 (e), ISSN:2349-3429 (p), DIP:18.01.014/20160401, ISBN:978-1-365-45447-9 